\title{
Fractures in Kuwait: incidence and distribution
}

\section{Fawaz Y Azizieh}

Department of Mathematics and Natural Sciences, International Centre for Applied Mathematics and Computational Bioengineering, College of Arts and Sciences, Gulf University for Science and Technology, Mubarak Al-Abdullah, Hawally, State of Kuwait
Correspondence: Fawaz Y Azizieh Department of Mathematics and Natural Sciences, International Centre for Applied Mathematics and Computational Bioengineering, College of Arts and Sciences, Gulf University for Science and Technology, Block 5, Building I, Mubarak Al-Abdullah Area/West Mishref, PO Box 7207, Hawally 32093, State of Kuwait

Tel +965 25307499

Fax +965 25307293

Email azizieh.f@gust.edu.kw
This article was published in the following Dove Press journal:

Risk Management and Healthcare Policy

14 June 2017

Number of times this article has been viewed

Abstract: The absence of descriptive epidemiological data on the frequency and distribution of fractures in a population is serious and may underestimate the actual importance of this public health problem. In this study, we report the crude and standardized incidence rates of fractures in the population of Kuwait during the period 2009-2012. Using the Ministry of Public Health's national registry, demographic data of all fracture cases between 2009 and 2012 were retrieved. These were further categorized into fractures at the hip or any other sites. Average annual incidence rates were calculated and standardized using the world's population in 2010 as a reference. Thus, 18,119 fractures among males and 6,362 among females were recorded. The overall estimated annual incidence rates of fractures per 100,000 person-years were 207 for males and 111.8 for females. Moreover, $13.3 \%$ of all fractures were in the hip, with incidence rates of 24.8 for males and 18.9 for females; while $86.7 \%$ were in other sites, with corresponding incidence rates of 182.2 and 92.8 , respectively. The age-specific fracture incidence rates in females remained below the corresponding rates of males until $\geq 50$ years of age, after which the female age groups showed successively higher rates. The age-standardized incidence rates for all fractures (hip and other sites) were 247.4 for males, 175.4 for females, and 216.2 for both sexes. The burden of this major public health challenge is set to rise, and such populationbased incidence data call for an urgent need for action to reduce the projected human impact and socioeconomic costs of fracture.

Keywords: age-standardized, Middle East, national registry, osteoporosis

\section{Introduction}

In the majority of cases, a bone fracture is either due to a high-impact trauma or a medical condition such as osteoporosis that causes the bone to be too weak to withstand even minimal stress. Fractures can occur in any bone in the body and may range from a hairline fracture, which is hard to detect and may heal with no medical interference, to more serious formats such as compound or open fractures that damage the surrounding skin or tissue.

Although a fracture can happen at any age, it is most common among the youth and the elderly. Every third child is expected to sustain at least 1 fracture before the age of 17 years, ${ }^{1}$ and fractures represent up to $9 \%$ of all injuries in children visiting health services. $^{2}$ For the elderly, 1 in 3 women and 1 in 5 men aged $\geq 50$ years will experience at least 1 osteoporotic fracture. ${ }^{3,4}$ Globally, during the year 2000, there were an estimated 9 million new fragility fractures, and rates are expected to further rise. ${ }^{5}$ While fracture sites and mechanisms of injury may not vary much between populations, studies have 
been reporting differences in incidence rates, secular trends, and patterns among populations of different countries, as well as between regions within the same country. ${ }^{6-8}$

It is accepted now that fractures, particularly osteoporotic ones, pose a major public health burden worldwide. Despite this, little is known about their epidemiology, and available publications report great variations..$^{7-9}$ For example, the agestandardized incidence rates of hip fracture vary more than 200-fold in women and more than 140-fold in men across countries in the world. ${ }^{9}$ Although there are many speculative interpretations for this marked heterogeneity, more epidemiological studies are certainly needed., ${ }^{7,9,10}$ Published epidemiological studies from the Middle East are few, while those from the Arabian Gulf Peninsula are even scarce and mostly focus on hip fractures, particularly in the elderly. ${ }^{11,12}$ For example, there is only 1 report from Kuwait about hip fracture rates among the young and the middle-aged groups, ${ }^{13}$ but none on the incidence rates of fractures at other sites.

The population pyramid of Kuwait is typical of "low mortality-high fertility" countries of the Middle East and North Africa regions. The total population in 2012 was 3.81 million and it is expected to increase up to 6 million by $2050 .{ }^{14}$ The life expectancy in 2011 was 74 years and is as well expected to increase to 78.3 years by $2050 .{ }^{15}$ Combining these 2 bits of information, the elderly population ( $\geq 50$ years of age) is expected to jump from $11.5 \%$ as in 2012 to $18.6 \%$ in 2020 , reaching $35.4 \%$ of the total population by $2050 .{ }^{12}$ As this demographic shift gradually comes about, heath care systems should be ready to accommodate the incomparable demands. The increase in the elderly population is of concern not only to Kuwait or the Middle East, but it is rather a worldwide challenge, and overcoming its accompanying consequences such as osteoporotic fractures is a major concern. By 2050, the worldwide incidence of hip fracture is projected to increase by $240 \%$ in women and $310 \%$ in men. ${ }^{16}$ It is worth mentioning that osteoporotic hip fractures account only for $\sim 20 \%$ of all osteoporotic fractures at all sites,${ }^{17}$ and therefore, the increase in the number of all fractures will be even more drastic.

On the other hand, while osteoporotic fractures are rare among the young and the middle age groups, fractures that are associated with trauma or injury are more common and increasing. ${ }^{12,13,16-18}$ The rates of deaths, trauma, or high-impact accidents and falls indirectly reflect the rate of fractures in these age groups. An international study on causes of death in 187 countries, from 1980 to 2010, showed that the fraction of global deaths due to injuries was higher in 2010 $(9.6 \%)$ compared to the earlier 2 decades $(8.8 \%) .{ }^{18}$ This was accompanied by a $46 \%$ rise in worldwide deaths due to road traffic accidents and a rise in deaths from falls. ${ }^{18}$ Compared to Western countries, Kuwait has a relatively young population structure, with $\sim 89 \%$ of the population below the age of 50 years (as per the national census of 2012). ${ }^{14}$ However, Kuwait is ranked in the top segment of countries with regard to trauma. In a 10-year study (from 2000 to 2009), 11,591 nonfatal road traffic injuries (RTIs) were reported, among which $28.2 \%$ were severe. The majority of RTI-related deaths were among males $(87.3 \%)$ in the age range of $20-59$ years $(70.8 \%){ }^{19}$

The absence of descriptive epidemiological data on the frequency and distribution of fractures in a population is serious and may underestimate the actual importance of this public health problem. In this study, we report the incidence of fractures of all types, study the age groups most affected, find male-to-female ratios for fractures, and stratify the results based on nationality among the population of Kuwait during the 4-year period of 2009-2012. We further report the age-standardized incidence rates, using the 2010 world population as a reference.

\section{Methods}

\section{Study population}

The National Center of Health Information (NCHI) in the Ministry of Public Health (MOPH) in Kuwait maintains basic statistical data relating to various vital and health indicators in the State of Kuwait (www.moh.gov.kw/ministry-statistics). The study population consisted of all fractures registered in the national registry database between January 1, 2009, and December 31, 2012. These were further categorized as hip fractures (International Classification of Diseases [ICD]-10 S72.0 and S72.1, corresponding to intracapsular/femoral neck or extracapsular/intertrochanteric fractures, respectively) or as fractures at all other sites. Patients were identified by their unique national civil identification number, which is linked to all other demographic data. The same patient was considered to be a new case only if he or she had a true second fracture unrelated to the primary one. As the data were deidentified, patient consent was not required, and the waiver of consent, along with the study, was approved by the institutional review board committee of the Gulf University for Science and Technology (GUST), Kuwait.

As per the census of $2012,{ }^{14}$ only $31.4 \%$ of Kuwait's population were Kuwaiti nationals, while $\sim 68.6 \%$ of the population were expatriates, among which $72 \%$ were from Asian non-Arab countries, $20 \%$ from other Arab countries, $5 \%$ from other African non-Arab countries, and 1\%-2\% from North 
America or other European countries (www.paci.gov.kw). The ratio of males to females in the total population was $1.5: 1 .^{20}$ In order to study the possible effect of the heterogeneous composition of the Kuwaiti population on fracture rates, this study stratified the analysis into Kuwaiti citizens and expatriates (non-Kuwaitis). Data were further stratified by sex, age groups, and types of fracture (hip or other sites).

In 2012, MOPH had 5 general hospitals plus 9 specialized hospitals; 94 primary health care clinics, and 73 diabetic clinics. Health care was also provided in Kuwait by 12 private sector hospitals and 3 hospitals belonging to the oil companies.

\section{Calculation of age-/sex-specific incidence rates}

The average annual crude age- and sex-specific incidence rates for all fractures in the years of 2009, 2010, 2011, and 2012 were calculated as detailed earlier. ${ }^{11}$ Fracture incidence rates per 100,000 person-years were calculated per site of fracture (hip and other sites), for each sex, nationality (Kuwaiti and non-Kuwaiti), and every 10-year age group distribution (ie, 10-19 years, 20-29 years, etc). This was done by dividing the total number of fractures recorded during the study period by the sum of the subpopulation of the same category in the respective years. The $95 \%$ confidence intervals (CIs) were calculated assuming a Poisson distribution.

To compare the incidence rates of fractures in Kuwait to those in other populations, we used the age-standardization method, ${ }^{21}$ which accounts for possible differences in the age distribution among populations. The age-standardized rates are the estimated incidence rates of fractures in Kuwait, if the Kuwaiti population at that time had the same age and sex structure as the standard population. Incidence rates presented were all standardized to the world's population in 2010, using the numbers reported by the United Nations (UN) (esa.un.org/unpd/wpp).

\section{Results}

Table 1 presents the numbers and crude incidence rates (per 100,000 person-years) of fractures among males and females in the 4-year period, as well as for each of the years from 2009 to 2012 . The total number of fractures of all types registered during the 4-year period of study was 24,481 , of which 18,119 (74\%) were among males and 6,362 (26\%) were among females (Table 1). Comparing the numbers of fractures between 2009 and 2012, we found a 14.8\% increase in the number of all fractures, associated with an increase in the number of the total population by $10.6 \%$ during the same period.

During the period of study, the combined (males and females) crude incidence rate per 100,000 person-years increased from 168.7 (CI: 164.3-173.1) in 2009 to 175.2 (CI: 170.9-179.5) in 2012, which represents an increase of $3.9 \%$. The average annual incidence rates of the years 2009-2012 were 207.0 (CI: 203.9-210) for males, 111.8 (CI: 109-114.6) for females, and 169.4 (CI: 167.3-171.6) for both sexes. The male: female (M: F) ratios for the crude incidence rates of fractures increased from 1.7 to 2.0 over the period of study, with an average of 1.9 (Table 1).

\section{Fracture sites}

Table 2 presents the total numbers and average annual incidence rates of fractures (hip and other sites) by 10-year age groups, sex, and nationality (Kuwaiti and non-Kuwaiti) during the study period (2009-2012).

Among the 24,481 fractures over the 4-year period of study, 3,246 (13.3\%) were in the hip, of which 2,168 (66.8\%) were among males and 1,078 (33.2\%) were among females. The incidence rates of hip fractures per 100,000 person-years of the total population were 24.8 (CI: 23.7-25.8) for males, 18.9 (CI: 17.8-20.1) for females, and 22.5 (CI: 21.7-23.3) for both sexes (males and females). The overall M: F ratio of hip fractures was 1.3 (Table 2).

On the other hand, the number of fractures at sites other than the hip over the same period of study was 21,235 (86.7\%), of which 15,951 (75.1\%) were among males and $5,284(24.9 \%)$ were among females. The incidence rates of fractures in sites other than the hip per 100,000 personyears of the total population were 182.2 (CI: 179.3-185.1)

Table I Numbers and crude incidence rates (per 100,000 person-years) of fractures among males and females from 2009 to 2012

\begin{tabular}{|c|c|c|c|c|c|c|c|c|c|c|c|}
\hline \multirow[t]{2}{*}{ Year } & \multicolumn{3}{|c|}{ Population } & \multicolumn{3}{|c|}{$\begin{array}{l}\text { No of all fractures } \\
\text { (hip + other sites) }\end{array}$} & \multicolumn{4}{|c|}{ Incidence rate } & \multirow[t]{2}{*}{$\begin{array}{l}\text { M:F } \\
\text { ratio }\end{array}$} \\
\hline & Males & Females & Combined & Males & Females & Combined & Males & Females & Combined & $95 \% \mathrm{Cl}$ & \\
\hline 2009 & $2,139,138$ & $\mathrm{I}, 303,807$ & $3,442,945$ & 4,298 & $|, 5| \mathrm{I}$ & 5,809 & 200.9 & 115.9 & 168.7 & $164.3-173.1$ & 1.7 \\
\hline 2010 & $2,|49,03|$ & $1,417,406$ & $3,566,437$ & 4,235 & $\mathrm{I}, 537$ & 5,772 & 197.1 & 108.4 & 161.8 & |57.6-|66.| & 1.8 \\
\hline 2011 & $2,183,669$ & $\mathrm{I}, 448,340$ & $3,632,009$ & 4,598 & 1,632 & 6,230 & 210.6 & 112.7 & 171.5 & $167.2-175.9$ & 1.9 \\
\hline 2012 & $2,283,153$ & $\mathrm{I}, 523,490$ & $3,806,643$ & 4,988 & 1,682 & 6,670 & 218.5 & 110.4 & 175.2 & |70.9-|79.5 & 2.0 \\
\hline $2009-2012$ & $8,754,991$ & $5,693,043$ & $14,448,034$ & 18,119 & 6,362 & $24,48 I$ & 207.0 & 111.8 & 169.4 & $|67.3-17| .6$ & 1.9 \\
\hline
\end{tabular}

Abbreviations: $\mathrm{Cl}$, confidence interval; $\mathrm{F}$, female; $\mathrm{M}$, male. 
Table 2 Numbers and age-specific incidence rates (per 100,000 person-years) of fractures in the hip and other sites, in Kuwait (2009-2012).

\begin{tabular}{|c|c|c|c|c|c|c|c|c|c|c|c|c|}
\hline \multirow{2}{*}{$\begin{array}{l}\text { Age } \\
\text { groups, } \\
\text { years }\end{array}$} & \multicolumn{5}{|l|}{ Males } & \multicolumn{5}{|l|}{ Females } & \multicolumn{2}{|c|}{ M:F ratio } \\
\hline & Population & $\begin{array}{l}\text { No of hip } \\
\text { fractures }\end{array}$ & Rate & $\begin{array}{l}\text { No of fractures } \\
\text { at other sites }\end{array}$ & Rate & Population & $\begin{array}{l}\text { No of hip } \\
\text { fractures }\end{array}$ & Rate & $\begin{array}{l}\text { No of fractures } \\
\text { at other sites }\end{array}$ & Rate & Hip & $\begin{array}{l}\text { Other } \\
\text { sites }\end{array}$ \\
\hline \multicolumn{13}{|l|}{ Kuwaitis } \\
\hline $0-9$ & 621,095 & 213 & 34.3 & 851 & 137.0 & 602,046 & 93 & 15.4 & 485 & 80.6 & 2.2 & 1.7 \\
\hline $10-19$ & 521,107 & 234 & 44.9 & $\mathrm{I}, 70 \mathrm{I}$ & 326.4 & 499,703 & 45 & 9.0 & 340 & 68.0 & 5.0 & 4.8 \\
\hline $20-29$ & 397,571 & 174 & 43.8 & 1,287 & 323.7 & 398,752 & 42 & 10.5 & 383 & 96.0 & 4.2 & 3.4 \\
\hline $30-39$ & 284,440 & 68 & 23.9 & 560 & 196.9 & 313,764 & 21 & 6.7 & 293 & 93.4 & 3.6 & 2.1 \\
\hline $40-49$ & 208,893 & 38 & 18.2 & 383 & 183.3 & 240,772 & 18 & 7.5 & 231 & 95.9 & 2.4 & 1.9 \\
\hline $50-59$ & 119,177 & 45 & 37.8 & 217 & 182.1 & 155,392 & 39 & 25.1 & 229 & 147.4 & 1.5 & 1.2 \\
\hline $60-69$ & 59,293 & 52 & 87.7 & 170 & 286.7 & 83,456 & 116 & 139.0 & 248 & 297.2 & 0.6 & 1.0 \\
\hline $79-79$ & 32,840 & 105 & 319.7 & 148 & 450.7 & 37,090 & $|4|$ & 380.2 & 174 & 469.1 & 0.8 & 1.0 \\
\hline$\geq 80$ & 9,748 & 84 & 861.7 & 50 & 512.9 & $|0,8| 4$ & 96 & 887.7 & 54 & 499.4 & 1.0 & 1.0 \\
\hline \multicolumn{13}{|c|}{ Non-Kuwaitis } \\
\hline $0-9$ & 484,399 & 119 & 24.6 & 514 & 106.1 & 460,265 & 72 & 15.6 & 317 & 68.9 & 1.6 & 1.5 \\
\hline $10-19$ & 352,652 & 98 & 27.8 & 919 & 260.6 & 311,215 & 27 & 8.7 & 176 & 56.6 & 3.2 & 4.6 \\
\hline $20-29$ & I,426,725 & 220 & 15.4 & 2,320 & 162.6 & 868,145 & 40 & 4.6 & 669 & 77.1 & 3.3 & 2.1 \\
\hline $30-39$ & $2,107,816$ & 233 & II.I & 3,059 & | $45 . \mid$ & 917,704 & 38 & 4.1 & 648 & 70.6 & 2.7 & 2.1 \\
\hline $40-49$ & I,367,30I & 180 & 13.2 & 2,306 & 168.7 & 534,345 & 29 & 5.4 & 538 & 100.7 & 2.4 & 1.7 \\
\hline $50-59$ & 593,897 & 113 & 19.0 & 1,063 & 179.0 & 184,184 & 45 & 24.4 & 246 & 133.6 & 0.8 & 1.3 \\
\hline $60-69$ & 137,913 & 85 & 61.6 & 311 & 225.5 & 51,664 & 66 & 127.7 & 129 & 249.7 & 0.5 & 0.9 \\
\hline $79-79$ & 25,675 & 67 & 261.0 & 66 & 257.1 & 17,109 & 88 & 514.3 & 66 & 385.8 & 0.5 & 0.7 \\
\hline$\geq 80$ & 4,449 & 40 & 899.1 & 26 & 584.4 & 6,623 & 62 & 936.1 & 58 & 875.7 & 1.0 & 0.7 \\
\hline \multicolumn{13}{|c|}{ Total population } \\
\hline All ages & 8,754,99| & 2,168 & 24.8 & $|5,95|$ & 182.2 & $5,693,043$ & $\mathrm{I}, 078$ & 18.9 & 5,284 & 92.8 & 1.3 & 2.0 \\
\hline
\end{tabular}

Abbreviations: $F$, female; $M$, male.

for males, 92.8 (CI: 90.3-95.4) for females, and 147 (CI: 145-149) for both sexes, with an overall M: F ratio of 2.0 (Table 2).

\section{Age-specific incidence rates of hip fracture}

Figure 1 presents the combined (males and females) percentage of fractures at the hip and other sites by 10 -year age groups in Kuwait during the study period (2009-2012). Among the young age groups, the highest percentage of hip fractures was in the age group of $<10$ years $(18.7 \%)$, ranging from $7.1 \%$ to $11.4 \%$ in the other young age groups, but increasing up to $60 \%$ in the elderly age groups of $\geq 80$ years (Figure 1).

Figure 2 presents the total number and average annual incidence rates of fractures (hip and other sites) by 10-year age groups by sex. In the young age groups ( $<50$ years), incidence rates of hip fracture were consistently higher among males than among females, with a peak of 30 per 100,000 person-years in males in the age group of 10-19 years (Figure 2). This male predominance was reversed in the elder age groups ( $\geq 50$ years), in which the incidence rates of hip

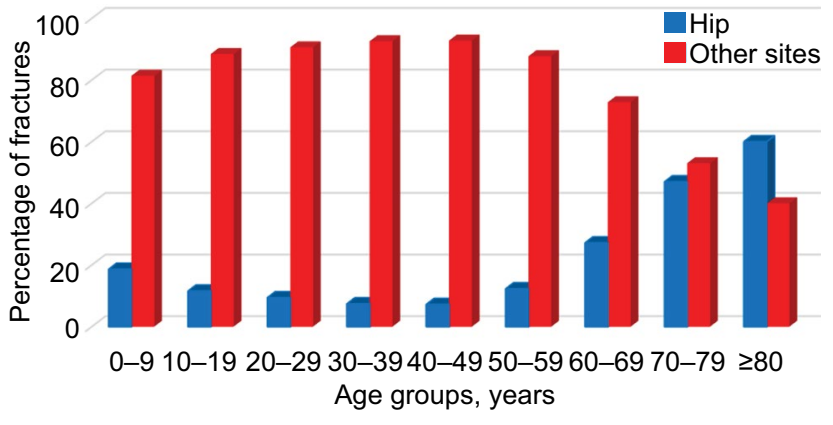

Figure I The percentage of fractures at the hip and at other sites by 10-year age groups in Kuwait, 2009-20I2.

fracture were consistently higher among females. However, there was a sharp rise in the incidence rates of hip fractures starting from the age group of 60-69 years onward for both sexes (Figure 2). The incidence rates per 100,000 personyears among females were $24.7,134.7,422.5$, and 906.1 in the age groups of 50-59 years, 60-69 years, 70-79 years, and $\geq 80$ years, respectively. The corresponding incidence rates among males were $22.2,69.5,293.9$, and 873.4 , respectively (Figure 2).

Although both the nationality subpopulations (Kuwaitis and non-Kuwaitis) showed a similar trend of hip fracture 


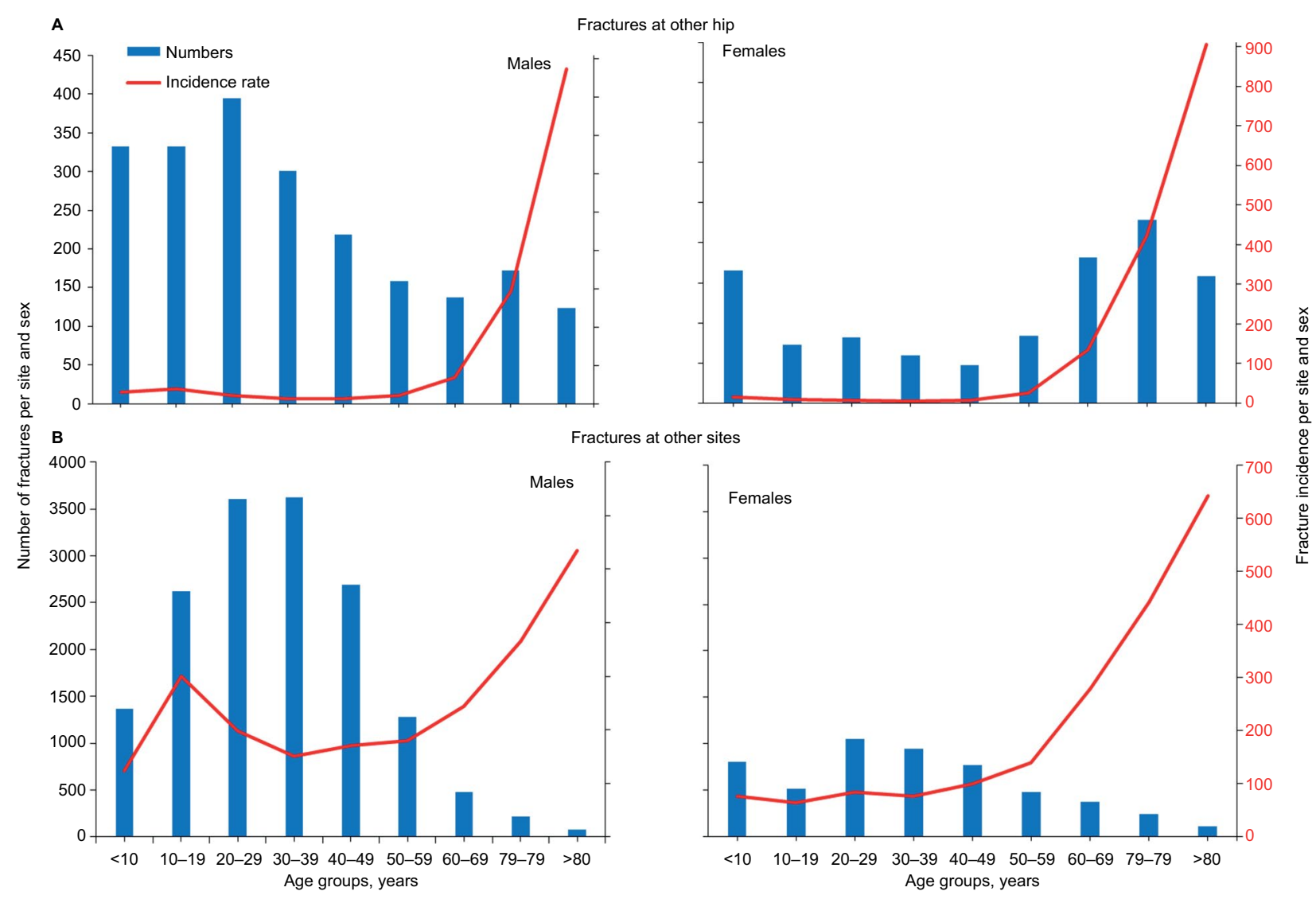

Figure 2 The number and incidence rates per 100,000 person-years of fracture at (A) the hip and (B) other sites by 10-year age groups among males and females in Kuwait, 2009-2012.

Notes: Bars represent the number of fractures corresponding to the left $Y$-axis scale. Lines represent the fracture incidence rate corresponding to the right $Y$-axis scale.

across the age groups among males and females, the incidence rates were consistently higher in the Kuwaiti subpopulation, except for the age group 70-79 years in females (380.2 versus 514.3) and the age groups of $\geq 80$ years in males (861.7 versus 899.1) and females (887.7 versus 936.1), wherein the incidence rates of hip fractures were higher in the non-Kuwaiti subpopulation (Table 2).

For the Kuwaiti subpopulation, the M: F ratio of hip fracture rates was the highest $(\mathrm{M}: \mathrm{F}$ ratio $=5)$ in the age group of 10-19 years, consistently declined with advancing age, reversed to 0.6 in the age group of 60-69 years, and reached 0.8 in the 70-79 year group and 1.0 in the age group of $\geq 80$ years (Table 2). The trend in the non-Kuwaiti subpopulation was similar, with the highest M: F ratio of 3.3 in the age group of 20-29 years, declining to $0.5,0.5$, and 1.0 in the age groups of 60-69 years, 70-79 years, and $\geq 80$ years, respectively. The M: F ratios were higher in the Kuwaiti subpopulation compared to non-Kuwaitis in all age groups, except the $40-49$ year and $\geq 80$ year groups, wherein they were equal.

\section{Age-specific incidence rates of fractures at other sites}

During the period of study, the highest percentage of fractures at other sites among the young age groups was in the age group of $40-49$ years $(92.9 \%)$. The percentages in the elderly age groups were $87.9 \%, 72.9 \%, 53 \%$, and $40 \%$ in the age groups of 50-59 years, 60-69 years, 70-79 years, and $\geq 80$ years, respectively (Figure 1 ).

As shown in Figure 2, the age-specific fracture incidence rates among females remained below the corresponding rates among males until the age group of 60-69 years, after which the female age groups showed successively higher rates than the corresponding groups of males.

In the young age groups ( $<50$ years), the highest peak of incidence rates for males was in the age group 10-19 years (299.9 per 100,000 person-years), while that of females was in the age group of 40-49 years ( 99.2 per 100,000 personyears). In the elderly age groups, the incidence rates increased sharply from 139.9 in the female age group of 50-59 years to 642.3 in the age group of $\geq 80$ years. The corresponding 
rates for males increased from 179.5 in the age group of $50-59$ years to 535.33 in the age group of $\geq 80$ years, per 100,000 person-years (Figure 2).

Both the Kuwaiti and the non-Kuwaiti subpopulations showed similar trends of fractures among males and females across the age groups. However, the incidence rates were consistently higher in the Kuwaiti subpopulation, except for the age groups spanning 40-49 years among females (95.9 versus 100.7$)$ and $\geq 80$ years among males (512.9 versus 584.4) and females (499.4 versus 875.7) (Table 2).

The M: F ratio of fracture incidence rates was the highest in the age group of 10-19 years for both Kuwaiti and non-Kuwaiti subpopulations (4.8 and 4.6, respectively). In the elderly age groups, the M:F ratios consistently declined from 1.2 in the Kuwaiti and 1.3 in the non-Kuwaiti groups in the age group of 50-59 years to 1.0 and 0.7 , respectively, in the age group of $\geq 80$ years (Table 2 ).

\section{Age-standardized incidence rates}

Table 3 presents the age-standardized incidence rates of fractures using the world's population structure in 2010 as a reference.

The age-standardized incidence rates of hip fractures for all populations (Kuwaitis and non-Kuwaitis) per 100,000 person-years were 45.1 for males, 52.5 for females, and 48.4 for both sexes, with an $\mathrm{M}$ : F ratio of 0.9 . The corresponding rates for fractures at other sites were 202.3, 122.9, and 167.8, respectively, with an $\mathrm{M}$ : F ratio of 1.6. The age-standardized incidence rates for all fractures (hip and other sites) were 247.4 for males, 175.4 for females, and 216.2 for both sexes, with an M: F ratio of 1.4.

The Kuwaiti subpopulation showed higher standardized fracture incidence rates in both hip and other sites compared to the non-Kuwaiti subpopulation. This was consistently shown for males, females, and the total subpopulation (Table 3).

\section{Discussion}

This study has reported age- and sex-specific fracture incident rates at all ages in Kuwait, using a large well-established national database over a period of 4 years (2009-2012). The study also reports the age-standardized rates using the world's population in 2010 as a reference. The only similar previous studies are limited to patients with hip fractures only. ${ }^{11,13}$ Studies from other countries have provided data on specific fractures, but the differences in demographic, socioeconomic, and environmental factors influence fracture incidence rates among different populations.

We report an increase of $14.8 \%$ in numbers and $3.9 \%$ in incidence rates for all fractures, which were associated with an increase of $10.6 \%$ among the total population in Kuwait during the 4-year period of the study. While this trend is alarming, looking into possible contributing factors is essential. These may include, but not be limited to, aging of the population, increased prevalence of overweight, climate changes, and lifestyle factors. During the same period of study, the elderly Kuwaiti subpopulation increased by $16.9 \%$ and the incidence rate of hip fractures among them increased by $37.2 \% .{ }^{11}$ Additionally, the prevalence of low bone mass among postmenopausal Kuwaiti women was reported to be higher than that seen in some European countries. ${ }^{22}$ The elderly population is further expected to represent $35.4 \%$ of the total population in Kuwait by $2050 .{ }^{12}$ Considering overweight as another possible contributing factor, Kuwait is among the countries with the highest obesity rates worldwide with studies showing prevalence up to $48 \% .{ }^{23}$ Although obese individuals have been considered protected against fractures, ${ }^{24}$ there is growing evidence that obesity is related to increased risk of fracture at different skeletal sites, which is partially independent from bone mineral density (BMD). ${ }^{25}$

Kuwait climate is characterized by long dry hot summers and short warm winters. While Kuwait is blessed with ambient sunshine all over the year, it is possible that the lifestyle and the harsh hot weather during the long summer discourage daily exposure to the sun, needed to maintain adequate vitamin D levels and bone quality. Approximately $86 \%$ of Kuwaiti females were reported to show hypovitaminosis D, ${ }^{26}$ and up to $60 \%$ of neonates had undetectably low vitamin D levels at delivery. ${ }^{27}$

RTIs have consistently been ranked the third most common cause of death among youth in Kuwait, with an average

Table 3 Age-standardized incidence rates of fractures in Kuwait, 2009-20I2

\begin{tabular}{|c|c|c|c|c|c|c|c|c|c|c|}
\hline \multirow[t]{2}{*}{ Fracture } & \multicolumn{3}{|c|}{ Kuwaitis } & \multicolumn{3}{|c|}{ Non-Kuwaitis } & \multicolumn{3}{|c|}{ All populations } & \multirow[t]{2}{*}{ M:F ratio } \\
\hline & Males & Females & Combined & Males & Females & Combined & Males & Females & Combined & \\
\hline Hip & 56.3 & 51.8 & 53.9 & 39.4 & 55.8 & 45.6 & 45.1 & 52.5 & 48.4 & 0.9 \\
\hline Other sites & 244.5 & 128.9 & 185.2 & 181.0 & 118.8 & 156.1 & 202.3 & 122.9 & 167.8 & 1.6 \\
\hline All sites & 300.7 & 180.7 & 239.1 & 220.4 & 174.5 & 201.7 & 247.4 & 175.4 & 216.2 & I.4 \\
\hline
\end{tabular}

Abbreviations: $F$, female; $M$, male. 
age of death between 21 years and 30 years, despite the heavy investment in transportation infrastructure, awareness, and existence of penalty point systems. ${ }^{19,28}$ Other causes of fractures at young age may include falls, sports, and workrelated activities. In 2012, the incidence rate of deaths in Kuwait, per 100,000 person-years, from transport-related accidents was 12.8 (18.8 for males and 3.8 for females), while that from other accidents was 10.7 (14.4 for males and 5.3 for females). ${ }^{20}$ Another retrospective study reported that accidental deaths constituted $85.7 \%$ of all cases of unnatural deaths, with RTI being the leading cause (64.6\%), followed by fall from heights $(13.1 \%){ }^{29}$

Interestingly, the incidence rates of both categories of fractures (hip and other sites) were much higher in males than in females. This is in line with previous reports ${ }^{2,6}$ and probably due to a combination of biological, social, and sex differences in lifestyle, working conditions, and risk-taking activities. We reported $74 \%$ of all fractures to be among males as opposed to $26 \%$ among females. This can be further explained by the much larger number of males than females in the population (Table 1). In 2012, the ratio of males to females in the total population was $1.5: 1 .^{20}$

Our data also support previous reports that showed variations in the incidence of fractures with age. ${ }^{1,6,30}$ Most of these epidemiological studies suggest bimodal fracture incidence, with peaks among the youth and the elderly. ${ }^{31}$ Although data on the cause of fracture did not form part of the current study, the incidence pattern reflects the established contributory factors, with sports, industrial accidents, and road traffic accidents being important in the younger age groups (explaining the male preponderance), while in the elder age groups, osteoporotic changes become predominant (explaining the higher incidence rates among females). However, we have reported a sharp rise in incidence rates of fractures in the elderly for both males and females, which confirms the equal vulnerability of both sexes to the aging process.

Several other studies have reported that $\sim 60 \%$ of fractures in young age groups are among boys, with the greatest incidence observed in the 10-14 year age group. ${ }^{1,6,32}$ Our data are in line with these records for both categories of fractures. The highest peak of fracture incidence at young age was that at sites other than the hip, among boys with an age range of 10-19 years.

In general, females showed a relatively uniform incidence of fractures up to the menopause and a rapid increase thereafter. In males, the pattern was different; there was a peak incidence in the age group of 10-19 years, followed by gradual decline in the following 2 age groups, with few variations in incidence in the age groups between 30 years and 59 years, but increasing again from the age group of 60-69 years onward. However, the peak incidence for the elderly males was lower than that for the elderly female (Figure 2). The highest fracture incidence in females was in the age group of $\geq 80$ years, with rates of 906.1 for hip fracture and 642.3 for fractures at other sites, while the respective rates in males were 873.4 and 535.3 per 100,000 person-years.

Kuwait and other Gulf countries are unique in terms of the heterogeneous composition of their populations (www. grc.net). This heterogeneity would imply variations in ethnicity, race, lifestyle, and duration of stay in the geographical area and therefore should be taken into consideration when analyzing the data. We stratified the data into Kuwaitis and non-Kuwaitis and reported similar trends for males and females in both categories of fractures. However, compared to the non-Kuwaiti subpopulation, the incidence rates were consistently higher in the Kuwaiti subpopulation in all the age groups, with the exception of the group of $\geq 80$ years. The higher incidence in this particular age group ( $\geq 80$ years) among the non-Kuwaitis may be explained by the majority of expatriates going back to their original home countries at advanced ages and with the relatively small number of the denominator, leading to apparent differences that are unlikely to be significant.

Several studies have shown potential relationships between ethnic and socioeconomic factors on the one hand and injuries such as fractures and sports- or recreationalrelated injuries on the other hand. ${ }^{33,34}$ Furthermore, international variations in incidence of fracture have been shown to have a latitudinal gradient, with an $\sim 1.9 \%-3 \%$ increment in hip fracture incidence for each $1^{\circ}$ latitude difference from the equator. ${ }^{8,35}$ While the Kuwaiti subpopulation studied is quite homogeneous, the expatriate subpopulations are very heterogeneous in several aspects, such as ethnicity, socioeconomic status, lifestyle, and duration of stay in the Kuwait geographical area. To reach further conclusions about the factors influencing the observed differences between the Kuwaiti and non-Kuwaiti subpopulations, it would be of interest to direct future studies toward comparing smaller, more homogeneous groups with respect to confounding factors not only related to demographics, but also related to socioeconomic, environmental, lifestyle, and other linked variables.

This and similar studies have several public policy implications for managing the burden of increasing fracture incidence rates. ${ }^{11-13,15-19}$ Many agencies worldwide adopt osteoporosis intervention thresholds based on BMD criteria. As per guidelines of the World Health Organization (WHO) 
and Adult Official Positions of the International Society for Clinical Densitometry (ISCD) (http://www.iscd.org/officialpositions/2015-iscd-official-positions-adult/) updated in 2015, subjects can be denoted as having normal BMD, osteopenia, or osteoporosis using T-score cutoffs (T-scores $\geq-1$, $2.5<\mathrm{T}$-scores $<-1, \mathrm{~T}$-scores $\leq-2.5$, respectively). As BMD has been considered the strongest predictor of fracture risk, ${ }^{36}$ T-score thresholds have been used in the Kuwaiti clinical guidelines for osteoporosis up to the 2014 version. However, as many risk factors have been recently identified to contribute to fracture risk regardless of BMD or T-score values (such as age, sex, prior fracture, family history of fracture, and other lifestyle risk factors), ${ }^{7}$ new algorithm-based assessment tools have been proposed. The Fracture Risk Assessment (FRAX $\left.{ }^{\circledR}\right)$ is a tool developed by the WHO to evaluate the fracture risk of patients (https://www.shef.ac.uk/FRAX). It provides estimates for a 10-year probability of fracture based on an individual's clinical risk profile. The output is a 10-year probability of a hip fracture and the 10-year probability of a major osteoporotic fracture (clinical spine, forearm, hip, or shoulder fracture). The FRAX calculation tool for Kuwait was launched recently. In this context, a new set of Kuwaiti guidelines with FRAX-based age-dependent intervention thresholds is under consideration.

To our knowledge, this is the first nationwide populationbased study of incidence of fractures in all age groups in Kuwait, using data from 4 consecutive years. These data may provide estimates of the public health impact of fractures, which will assist in planning health services and estimating national fracture costs. It can be further used to compare the age-standardized incidence rates with future local, regional, and international epidemiological studies.

The study, however, has some limitations. First, data on the type and cause of fractures were lacking. Further, fracture data were imported in only 2 categories: hip or other sites. Second, the data are presented in 10-year age intervals because the 5-year age interval data were not available. Third, the NCHI registry would have missed those subjects who encountered asymptomatic fractures or simpler fractures who were treated by small private orthopedic clinics or private hospitals, patients who were discharged from the emergency department without being given an appointment to the fracture clinics, and people who died with unsuspected or undiagnosed fractures. Finally, epidemiological studies have to be interpreted with caution as several factors such as underlying variations in demographic, socioeconomic, and climatic conditions may vary between different studies.

\section{Conclusion}

The data presented here focused on fracture epidemiology in Kuwait using the governmental registry data from the period 2009-2012. The burden of this major public health challenge is set to rise, not only in Kuwait, but also in other parts of the Middle East in particular and worldwide in general. Such reports call for an urgent need for action to reduce the projected human impact and socioeconomic cost of fractures.

\section{Acknowledgments}

This study was made possible by the help of Dr Abdullah M Al-Ajeel, the Director of the Medical Statistical Analysis Department, Ministry of Public Health, Kuwait, who thankfully provided the Ministry's fracture registry data for the years 2009, 2010, 2011, and 2012. This study was funded by Kuwait Foundation for the Advancement of Sciences (KFAS) project grant (number 2013-1302-02).

\section{Disclosure}

The author reports no conflicts of interest in this work.

\section{References}

1. Cooper C, Dennison EM, Leufkens HG, Bishop N, van Staa TP. Epidemiology of childhood fractures in Britain: a study using the general practice research database. J Bone Miner Res. 2004;19(12): 1976-1981.

2. Spady DW, Saunders DL, Schopflocher DP, Svenson LW. Patterns of injury in children: a population-based approach. Pediatrics. 2004;113(3 pt 1):522-529.

3. Melton LJ 3rd, Atkinson EJ, O'Connor MK, O'Fallon WM, Riggs BL. Bone density and fracture risk in men. $J$ Bone Miner Res. 1998;13(12):1915-1923.

4. Melton LJ 3rd, Chrischilles EA, Cooper C, Lane AW, Riggs BL. Perspective. How many women have osteoporosis? J Bone Miner Res. 1992;7(9):1005-1010.

5. Johnell O, Kanis JA. An estimate of the worldwide prevalence and disability associated with osteoporotic fractures. Osteoporos Int. 2006;17(12):1726-1733.

6. Hedstrom EM, Svensson O, Bergstrom U, Michno P. Epidemiology of fractures in children and adolescents. Acta Orthop. 2010;81(1):148-153.

7. Kanis JA, Oden A, McCloskey EV, et al; IOF Working Group on Epidemiology and Quality of Life. A systematic review of hip fracture incidence and probability of fracture worldwide. Osteoporos Int. 2012;23(9):2239-2256.

8. Oden A, Kanis JA, McCloskey EV, Johansson H. The effect of latitude on the risk and seasonal variation in hip fracture in Sweden. $J$ Bone Miner Res. 2014;29(10):2217-2223.

9. Cauley JA, Chalhoub D, Kassem AM, Fuleihan Gel H. Geographic and ethnic disparities in osteoporotic fractures. Nat Rev Endocrinol. 2014;10(6):338-351.

10. Johnell O, Borgstrom F, Jonsson B, Kanis J. Latitude, socioeconomic prosperity, mobile phones and hip fracture risk. Osteoporos Int. 2007;18(3):333-337.

11. Azizieh FY. Incidence of hip fracture in Kuwait: a national registrybased study. Arch Osteoporos. 2015;10:40.

12. Fuleihan GE, Adib MG, Nauroy L. The Middle-East \& Africa Regional Audit. Epidemiology, Costs \& Burden of Osteoporosis in 2011; 2011 Springer. London, UK. 
13. Memon A, Pospula WM, Tantawy AY, Abdul-Ghafar S, Suresh A, Al-Rowaih A. Incidence of hip fracture in Kuwait. Int J Epidemiol. 1998;27(5):860-865.

14. Health \& Vital Statistics Division NCoHI, Ministry of Public Health, Kuwait. Kuwait Health Indicators 2003-2013. 2014. Kuwait.

15. Younis M, Al-Hajeri M, Celik Y, Kisa A, Richard P, Parkash J. Healthcare of aging population of Kuwait. Ageing Int. 2015;40(1):36-43.

16. Gullberg B, Johnell O, Kanis JA. World-wide projections for hip fracture. Osteoporos Int. 1997;7(5):407-413.

17. Strom O, Borgstrom F, Kanis JA, et al. Osteoporosis: burden, health care provision and opportunities in the EU: a report prepared in collaboration with the International Osteoporosis Foundation (IOF) and the European Federation of Pharmaceutical Industry Associations (EFPIA). Arch Osteoporos. 2011;6:59-155.

18. Lozano R, Naghavi M, Foreman K, et al. Global and regional mortality from 235 causes of death for 20 age groups in 1990 and 2010: a systematic analysis for the Global Burden of Disease Study 2010. Lancet. 2012;380(9859):2095-2128.

19. Ziyab AH, Akhtar S. Incidence and trend of road traffic injuries and related deaths in Kuwait: 2000-2009. Injury. 2012;43(12):2018-2022.

20. Ministry of Health SoK. Health, Kuwait. National Center of Health Information. 49th Edition, National Center of Health Information, Ministry of Health. 2012. Kuwait.

21. Armitage P, Berry G, Matthews JNS. Statistical methods in epidemiology. Statistical Methods in Medical Research. Blackwell Science Ltd; 2008:648-716. Blackwell Science Ltd. Oxford, UK.

22. Gupta R, Al-saeed O, Azizieh F, Albusairi A, Gupta P, Mohammed A. Evaluation of bone mineral density in postmenopausal women in Kuwait. J Clin Densitom. 2012;15(2):211-216.

23. Karageorgi S, Alsmadi O, Behbehani K. A review of adult obesity prevalence, trends, risk factors, and epidemiologic methods in Kuwait. J Obes. 2013;2013:378650.

24. Tang X, Liu G, Kang J, et al. Obesity and risk of hip fracture in adults: a meta-analysis of prospective cohort studies. PLoS One. 2013;8(4):e55077.
25. Gonnelli S, Caffarelli C, Nuti R. Obesity and fracture risk. Clin Cases Miner Bone Metab. 2014;11(1):9-14.

26. Alyahya K, Lee WT, Al-Mazidi Z, Morgan J, Lanham-New S. Risk factors of low vitamin D status in adolescent females in Kuwait: implications for high peak bone mass attainment. Arch Osteoporos. 2014;9:178.

27. Molla AM, Al Badawi M, Hammoud MS, et al. Vitamin D status of mothers and their neonates in Kuwait. Pediatr Int. 2005;47(6): 649-652.

28. El-Shazly M, Makboul G, El-Sayed A. Life expectancy and cause of death in the Kuwaiti population 1987-2000. East Mediterr Health J. 2004;10(1-2):45-55.

29. Al-Kandary N, Al-Waheeb S. Patterns of accidental deaths in Kuwait: a retrospective descriptive study from 2003-2009. BMC Public Health. 2015;15:302.

30. Rennie L, Court-Brown CM, Mok JY, Beattie TF. The epidemiology of fractures in children. Injury. 2007;38(8):913-922.

31. Cooper C. Epidemiology and public health impact of osteoporosis. Baillieres Clin Rheumatol. 1993;7(3):459-477.

32. Hedström EA, Waernbaum IA. Incidence of fractures among children and adolescents in rural and urban communities: analysis based on 9,965 fracture events. Inj Epidemiol. 2014;1(1):14.

33. Ni H, Barnes P, Hardy AM. Recreational injury and its relation to socioeconomic status among school aged children in the US. Inj Prev. 2002;8(1):60-65.

34. Lyons RA, Delahunty AM, Heaven M, McCabe M, Allen H, Nash P. Incidence of childhood fractures in affluent and deprived areas: population based study. BMJ. 2000;320(7228):149.

35. Grant WB. Variations in solar UVB doses and serum 25-hydroxyvitamin D concentrations may explain the worldwide variation in hip fracture incidence. Osteoporos Int. 2012;23(9):2399-2400; author reply 2401-2392.

36. Johnell O, Kanis JA, Oden A, et al. Predictive value of BMD for hip and other fractures. J Bone Miner Res. 2005;20(7):1185-1194.
Risk Management and Healthcare Policy

\section{Publish your work in this journal}

Risk Management and Healthcare Policy is an international, peer-reviewed open access journal focusing on all aspects of public health, policy, and preventative measures to promote good health and improve morbidity and mortality in the population. The journal welcomes submitted papers covering original research, basic science, clinical and epidemiological

\section{Dovepress}

studies, reviews and evaluations, guidelines, expert opinion and commentary, case reports and extended reports. The manuscript management system is completely online and includes a very quick and fair peerreview system, which is all easy to use. Visit http://www.dovepress.com/ testimonials.php to read real quotes from published authors. 